\title{
Defective Replication of Psoralen Adducts Detected at the Gene-Specific Level in Xeroderma Pigmentosum Variant Cells
}

\author{
R. RITA MISRA, ${ }^{1} \dagger$ AND JEAN-MICHEL H. $\operatorname{VOS}^{1,2 *}$ \\ UNC-Lineberger Comprehensive Cancer Center ${ }^{1}$ and Department of Biochemistry and Biophysics, ${ }^{2}$ \\ University of North Carolina at Chapel Hill, North Carolina 27599-7295
}

Received 9 June 1992/Returned for modification 12 October 1992/Accepted 4 November 1992

\begin{abstract}
Replication of damaged DNA is suspected to play an important role in cell cycle, genetic stability, and survival pathways. Using psoralen photoaddition as prototype DNA damage and the renaturing agarose gel electrophoresis technique to measure DNA cross-linking in individual genes, Vos and Hanawalt previously observed efficient bypass replication of psoralen monoadducts in human genes (J.-M. H. Vos and P. C. Hanawalt, Cell 50:789-799, 1987). To understand the mechanism of bypass replication in human cells, mutants affected in such a process would be useful. We now report that cells from individuals sufiering from the hereditary recessive syndrome xeroderma pigmentosum variant (XPV) are hypersensitive to killing induced by photoactivated psoralen. In addition, analysis of psoralen-mediated DNA cross-linking in the rRNA genes indicated that although repair of psoralen adducts was similar to that of normal individuals, XPV cells were markedly deficient in the ability to bypass psoralen adducts during replication; in comparison with normal cells, approximately half as many monoadducts were bypassed during replication in XPV cells. Furthermore, in contrast to normal cells, replication of interstrand cross-links was not detected in XPV. This is the first demonstration of a deficiency in bypass replication detected at the gene-specific level in vivo. A model involving a strand-specific defect in recombinational bypass in XPV is proposed.
\end{abstract}

DNA damage in living organisms can result in birth defects, cancer, or lethality. Furthermore, existing data suggest that relaxation in the control over DNA replication plays a critical role in determining the pathological response. For example, errors leading to mutation most often arise during $S$ phase $(16,21)$, highly proliferative cells appear to be more susceptible to neoplastic transformation than nonproliferating cells (13), and overreplication of DNA seems to promote genetic instability (24). As of yet, however, the cellular response to damage encountered at the replication fork, particularly in eukaryotes, is poorly understood (reviewed in reference 32 ).

The existence of several human, hereditary cancer-prone diseases further suggests that abnormal processing of DNA damage may be an essential factor in the induction of genetic alterations (14). Xeroderma pigmentosum (XP) exemplifies such a disease. An autosomal, recessively inherited disorder, XP affects between 1 in 40,000 and 1 in 200,000 individuals worldwide. XP patients are identified by a marked hypersensitivity to $254-\mathrm{nm}$ UV radiation, resulting in malignancies of the eyes and sun-exposed areas of the skin, frequent neurological complications, and premature death. So far, eight genetic complementation groups have been identified for XP, indicating that at least eight different genes may be involved (reviewed in references 4,11 , and 30 ). Although deficiencies in the ability to remove damage from cellular DNA appear to be responsible for most cases of XP, individuals suffering from the variant form of XP (XPV) have no obvious defect in DNA repair. XPV cells do, however, exhibit moderate hypersensitivity to killing induced by UV light and exaggerated delays in the recovery of DNA syn-

\footnotetext{
* Corresponding author.

† Present address: Curriculum in Toxicology, University of North Carolina at Chapel Hill, NC 27599-7400.
}

thesis after treatment with UV light $(17,23)$. Like those with classical XP, XPV individuals suffer from an increased risk of skin cancer, although the average age of onset for XPV appears later, i.e., 15 and 53 years, respectively $(4,11)$. XPV cells are therefore uniquely well suited for use in experiments aimed at elucidating the relationship between cellular transformation and aberrant replication of damaged DNA.

Previous studies have demonstrated an abnormal replication pattern in XPV cells after irradiation with UV light (17, 23). Although a replication defect in XPV has been proposed $(17,23)$, no study has directly compared the ability of the replication fork to bypass UV-induced damage in normal and XPV cells. Our strategy to understand the molecular defect in XPV was based on the use of photoactivated $4^{\prime}$-hydroxymethyl $4,5^{\prime}, 8$-trimethyl psoralen (HMT) as a model DNA-damaging agent. Since photoactivated HMT produces adducts that are structurally quite similar to UV-induced pyrimidine dimers (3), we suspected that XPV cells might be particularly sensitive to this agent. In addition, the spectrum of lesions produced by HMT is well defined, limited to intrastrand monoadducts (MAs) and interstrand cross-links (XLs) in the genetic material $(31,33)$. Finally, psoralen MAs represent a unique lesion, since the bypass efficiency can be accurately measured at the gene-specific level in cultured mammalian cells (31), and this bypass level is found to be extremely high in mammalian genes $(33,38)$.

Analysis at the gene-specific level was performed to distinguish whether XPV cells are defective in bypassing or removing damage encountered at the replication fork. The renaturing agarose gel electrophoresis (RAGE) technique $(31,33)$ was used to monitor induction, removal, and replicational bypass of HMT adducts in the rRNA genes of normal and XPV cells. Psoralen-induced intrastrand adducts are bypassed at an efficiency of 80 to $100 \%$ during replication 
of the rRNA genes in normal mammalian cells (38), and tightly regulated expression of the rRNA locus is critical for normal cell function, differentiation, and growth (26). Together, such observations suggest that the rRNA genes are particularly good loci to use in studies aimed at understanding how functional DNA processing systems prevent neoplastic transformation.

We report that XPV cells are hypersensitive to the cytotoxic effects of photoactivated psoralen. In addition, although we found no differences in induction or removal of psoralen-induced DNA damage between normal and XPV cells, the XPV cells exhibited a marked deficiency in the ability to bypass psoralen adducts during replication. Our results represent the first report of a defect in bypass replication detected at the gene-specific level in a human cell line. We speculate that this defect, as applied to UV-induced damage, may ultimately be responsible for the increased susceptibility to UV-induced carcinogenesis observed in individuals with XPV.

\section{MATERIALS AND METHODS}

Cell cultures. The XPV lymphoblastoid cell line GM0 2449A was obtained from the National Institute of General Medical Sciences Human Genetic Mutant Cell Repository (Camden, N.J.). Normal human lymphoblastoid cell lines UC729-6 (UC) and HSC93 were gifts from R. Levy and M. Buchwald, respectively. Cells were grown in suspension in a humidified atmosphere at $37^{\circ} \mathrm{C}$ and $5 \% \mathrm{CO}_{2}$ in RPMI 1640 medium supplemented with $10 \%$ fetal calf serum, glutamine, and antibiotics. Cultures were routinely split twice per week and seeded at a density of $2 \times 10^{5}$ to $3 \times 10^{5}$ cells per 100-mm-diameter dish.

Assay of HMT-induced cytotoxicity. The protocol used for monitoring chemically induced inhibition of cell growth has been described previously (20) and is similar to the viability test used to document the UV sensitivity of XPV lymphoblastoid lines (22). Briefly, growing cells were diluted to a concentration of $2 \times 10^{5} / \mathrm{ml}$ and seeded into individual wells of a 24-well plate. The various doses of HMT (HRI Associates, Berkeley, Calif.) were administered to cells in phosphate-buffered saline and were activated in situ by a single 5-min exposure to 360-nm ultraviolet (UVA) light, and the unbound HMT was subsequently washed away. Cells in the first experimental group (PUVA-1 group) were then returned to $37^{\circ} \mathrm{C}$ and allowed to recover for various lengths of time. Cells in the second experimental group (PUVA-2 group) received an additional $15 \mathrm{~min}$ of UVA irradiation prior to recovery, immediately after removal of unbound HMT. Previous work has shown that PUVA-1 treatment produces a high (9:1) ratio of cross-linkable MAs to interstrand XLs in DNA, and that most $(70 \%)$ of these MAs are converted to XLs during the second UVA irradiation of PUVA-2-treated cells $(31,33,34)$. By using a Coulter Counter, increases in cell number were monitored over a period of 2 weeks. For both experimental groups, cell growth was monitored 1, 4, 7, and 14 days posttreatment and reported directly as cell numbers per milliliter of culture.

Gene-specific analysis of induction, removal, and replicational bypass of HMT-induced damage. The experimental scheme used to monitor cellular processing of HMT MAs and XLs in specific fragments of DNA has been described previously $(31,33)$. In damage induction studies, cells were lysed immediately after PUVA-1 treatment to determine the initial level of damage in cellular DNA. In damage removal and replicational bypass studies, a portion of each cell type underwent an additional 24-h posttreatment incubation in fresh medium containing $10 \mu \mathrm{M}$ bromodeoxyuridine and 1 $\mu \mathrm{M}$ fluorodeoxyuridine in order to incorporate density label into newly synthesized DNA. After treatment, cells were lysed overnight at $37^{\circ} \mathrm{C}$ in a buffer containing $10 \mathrm{mM}$ Tris, 1 mM EDTA, $0.5 \%$ sodium dodecyl sulfate (pH 8), and $0.1 \mathrm{mg}$ of proteinase $\mathrm{K}$ per $\mathrm{ml}$, and cell lysates were treated with heat-inactivated RNase A. High-molecular-weight DNA was subsequently purified by phenol-chloroform extraction and ethanol precipitation and digested with restriction endonuclease EcoRI.

In damage removal and bypass studies, unreplicated (light-light [LL]) fragments of DNA were separated from replicated (heavy-light [HL]) fragments of DNA by using two successive, isopycnic $\mathrm{CsCl}$ density gradients. Individual LL and HL samples were then dialyzed overnight, and DNA concentrations were determined by $A_{260}$ and/or the Hoechst dye method (2). In all experiments, the RAGE technique was used to separate chemically cross-linked and un-cross-linked fragments of DNA. After separation, the DNA was transferred to nylon membranes (Micron Separations Inc., Westboro, Mass.) and hybridized to a ${ }^{32} \mathrm{P}$-labeled probe as instructed by the manufacturer. The plasmid probe used in these studies, $\mathrm{pC}_{\mathrm{EB}}$, was provided by J. Sylvester; $\mathrm{pC}_{\mathrm{EB}}$ detects a 10.7-kb EcoRI fragment that begins upstream from, and includes, the $5^{\prime}$ end of the human repetitive rRNA gene (15). Quantitation of autoradiogram band intensities was achieved with a scanning densitometer (LKB 2222-020 Ultroscan XL, equipped with Gel Scan XL software). To compensate for the detection limits of the X-ray film, both long and short exposures were often performed; in such cases, band intensities were standardized to correct for differences in the lengths of $\mathrm{X}$-ray exposure and radioactive decay.

To determine the absolute level of psoralen damage in the rRNA loci of cells treated with various doses of HMT, the mean numbers of XLs and MAs per fragment were calculated by using the following equations derived from a Poisson distribution (31):

$$
\mathrm{XL}=-\ln (1-\mathrm{RF})
$$

where XL represents the number of XLs per fragment and RF represents the fraction of renatured DNA, and

$$
\mathrm{MA}=\left[\mathrm{XL}_{\mathrm{uva}}-\mathrm{XL}\right]=\left[\ln (1-\mathrm{RF})-\ln \left(1-\mathrm{RF}_{\mathrm{uva}}\right)\right]
$$

where MA represents the number of MAs per fragment, XL and $X L_{u v a}$ represent the number of XLs per fragment before and after in vitro UVA, respectively, and $R F$ and $R F_{u v a}$ represent the fraction of renatured DNA before and after ir vitro UVA respectively.

For the quantitation of PUVA-mediated modification of specific genomic fragments, the following equation was used to determine the levels of XLs and MAs per fragment at the various HMT concentrations (31):

$$
\mathrm{RF}=\mathrm{DS} /(\mathrm{DS}+\mathrm{SS})
$$

where DS is the intensity of the double-strand band and SS is the intensity of the single-strand band in an alkali-treated sample of DNA. The mean number of XLs per fragment is derived from the alkali denatured samples, whereas the mean number of MAs per fragment is derived from the in vitro extensively UVA-irradiated and denatured samples, after subtraction of the mean number of XLs per fragment. 
For the quantitation of repair and replication of PUVAinduced adducts on specific genomic fragments, the following equation was used to compare the levels of psoralen damage between 0 and $24 \mathrm{~h}$ in unreplicated DNA and between unreplicated (LL) and replicated DNA (HL) at $24 \mathrm{~h}$, respectively (31):

$$
\mathrm{RF}=\mathrm{DSa} / \mathrm{DSn}
$$

where DSn is the intensity of the double-strand band in a neutral sample, and DSa is the intensity of the double-strand band in an alkali-treated sample of the same fraction of DNA. As for equation 3, the frequency of XLs is determined directly from denatured DNA and the frequency of MAs is determined from the additional XLs produced by extensively irradiating the DNA in vitro, prior to RAGE.

The efficiency of repair refers to the fraction of lesions removed from unreplicated DNA during the 24-h recovery period and has been defined previously $(31,35)$. The efficiency of replicational bypass refers to the fraction of damage remaining in newly synthesized DNA, multiplied by 2 to correct for semiconservative replication $(31,38)$, and is calculated as follows:

$$
\text { bypass efficiency }=\left[\left(\mathrm{MA}_{\mathrm{HL}} / \mathrm{MA} \mathrm{LL}_{\mathrm{L}}\right) \times 2\right]
$$

where $\left(\mathrm{MA}_{\mathrm{HI}} / \mathrm{MA}_{\mathrm{LI}}\right)$ represents the fraction of MAs in replicated DNA relative to unreplicated DNA $24 \mathrm{~h}$ after psoralen exposure with $M A_{H L}$ and $M A_{L L}$ defined as in equation 2 .

\section{RESULTS}

Psoralen-induced inhibition of normal and XPV cell growth. To determine whether XPV cells are hypersensitive to psoralen treatment, dose-response experiments were performed by using a well-established assay to measure inhibition of cell growth $(20,22)$. Data collected from five independent experiments during a 2-week period after PUVA treatment are summarized in Fig. 1. As shown, similar trends in the inhibition of growth of normal and XPV cells were observed 4,7 , or 14 days after psoralen exposure. In experiments using conditions that produce 80 to $90 \%$ MAs in cellular DNA (PUVA-1 experiments [34]), a single administration of $0.01 \mu \mathrm{g}$ of photoactivated HMT per ml inhibited the growth of XPV cell cultures by $95 \%$; in contrast, the same dose caused less than $40 \%$ reductions in the growth of two different normal cell lines. Differences between normal and XPV cells could not be accurately assessed at higher PUVA-1 doses; at such doses, growth of all three lines fell to within the variation in initial seeding of culture wells. In a second series of experiments using conditions that produce approximately $70 \%$ XLs in cellular DNA (PUVA-2 experiments [34]), XPV hypersensitivity was apparent at the intermediate HMT doses of 0.003 and $0.005 \mu \mathrm{g} / \mathrm{ml}$. At these doses, growth of XPV cultures was inhibited by 84 and $94 \%$, respectively, whereas growth of normal cells was inhibited by only 34 and $67 \%$, respectively. Again, at higher PUVA-2 doses, differences between normal and XPV cells were obscured. Finally, although PUVA-2 conditions appeared to kill both normal and XPV cells more efficiently than did PUVA-1 conditions, XPV hypersensitivity relative to normal cells was more pronounced under PUVA-1 conditions than under PUVA-2 conditions. This last observation suggests that XPV cells are more hypersensitive to MAs than to $\mathrm{XLs}$ in the genetic material.

Induction of psoralen MAs and XLs in the rRNA loci of normal and XPV cells. To determine whether an increased level of DNA modification is responsible for XPV hypersensitivity to PUVA, initial levels of psoralen-induced MAs and XLs were measured in the rRNA loci of normal (HSC93) and XPV cells, using the RAGE procedure (Fig. 2a). This method allows quantitation of extremely low levels of crosslinking in specific DNA sequences (31). As shown in Fig. 3a, the levels of PUVA-1-induced DNA MAs and XLs are visualized as rapidly renaturing double-stranded DNA fragments after alkali denaturation, with or without in vitro UVA irradiation. As shown in Fig. 3b, no significant differences in XL levels were detected between normal and XPV lines. Although a cell-specific difference in MA level was apparent at the highest HMT dose tested $(3 \mu \mathrm{g} / \mathrm{ml})$, at that dose, the MA level in normal cells exceeded the level detected in XPV cells. Such results indicate that the DNAs of normal and XPV cells are equally accessible to HMT modification and support the conclusion that an increased susceptibility to induction of DNA damage is not responsible for XPV hypersensitivity to PUVA. As expected, our results also confirmed that a single, short UVA photoactivation step favors formation of HMT MAs over XLs in cellular DNA; on the average, MA levels were fourfold higher than XL levels throughout the dose range used.

Removal of HMT adducts in the rRNA loci of normal and XPV cells. To determine whether a defect in the ability to repair psoralen damage is responsible for XPV hypersensitivity to PUVA-1, the amount of damage removed from the rRNA genes was assessed $24 \mathrm{~h}$ after treatment by the procedure described in Fig. 2b. Inspection of Fig. 4 revealed a decrease in the fractions of both MAs and XLs after $24 \mathrm{~h}$. In addition, removal of psoralen adducts from the rRNA genes appeared similar in normal and XPV cells. After quantitation by densitometer scanning as described in the Materials and Methods, we determined that the efficiency of MA removal approached $30 \%$, and that the efficiency of XL removal approached $70 \%$, in both cell lines. Taken together, such results indicate that a defect in removal of DNA damage is not responsible for XPV hypersensitivity to PUVA-1.

Bypass replication of HMT adducts in the rRNA loci of normal and XPV cells. To determine whether a defect in replicational bypass of DNA damage is responsible for XPV hypersensitivity to PUVA-1, levels of damage in replicated and unreplicated fragments of DNA were monitored $24 \mathrm{~h}$ after exposure, using the assay outlined in Fig. $2 \mathrm{~b}$. The results are presented in Fig. 5 and quantified in Table 1. Inspection of Fig. 5 revealed that the fraction of crosslinkable fragments in the replicated DNA of normal cells was

FIG. 1. Hypersensitivity of XPV cells to treatment by photoactivated psoralen. Control HSC93 (a and d) and UC (b and e) cells and XPV cells ( $c$ and $f$ ) were exposed to various HMT concentrations and treated with a single (a to c) or double (d to f) irradiation as described in Materials and Methods. Cell growth was monitored 1, 4, 7, and 14 days posttreatment, and the average values of two to five independent experiments with standard deviations are reported as cell numbers per milliliter of culture. For PUVA-1 experiments, cells were untreated $(-)$ or given an HMT dose of $0.005(\ldots \ldots), 0.01(--)$, or $0.1(--,) \mu \mathrm{g} / \mathrm{ml}$; for PUVA-2 experiments, cells were untreated $(-)$ or given an HMT dose of $0.003(\ldots \ldots), 0.005(--)$, or $0.01(--\infty) \mu \mathrm{g} / \mathrm{ml}$. 


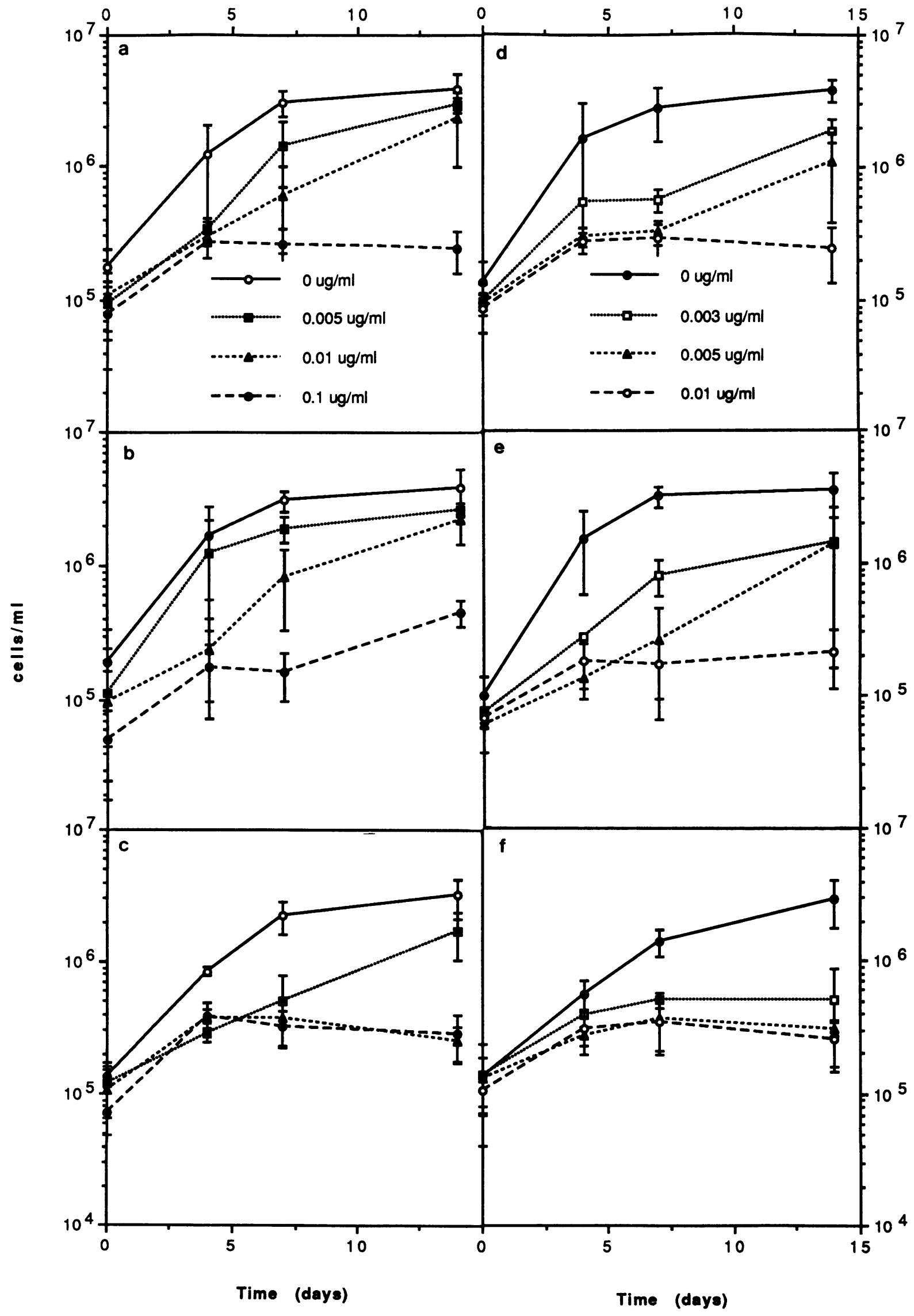

$\frac{\bar{E}}{\frac{0}{0}}$ 

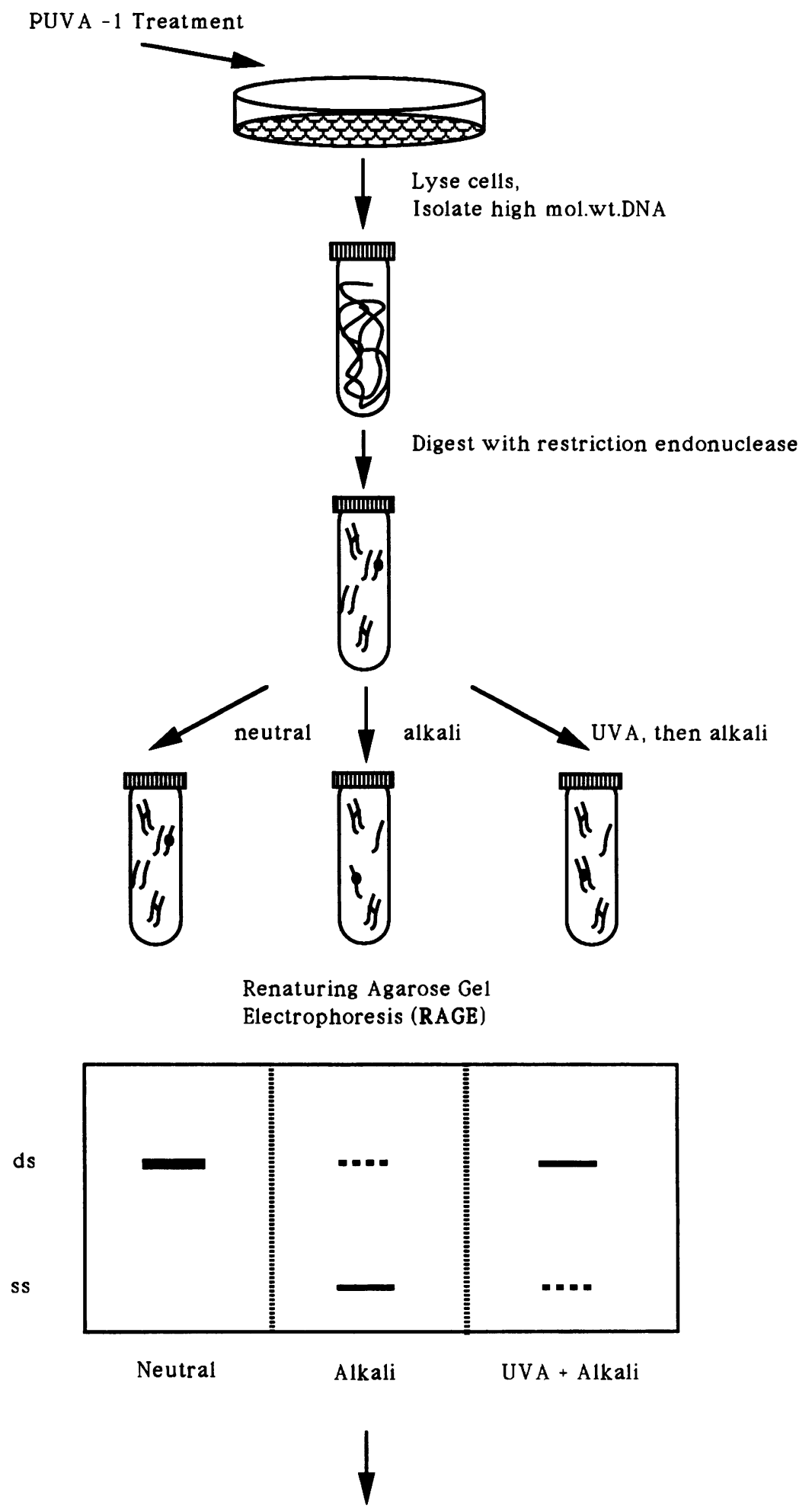

Transfer DNA to nylon membrane

Hybridize with 32P-labelled Probe - Autoradiograph and quantitate band intensities by densitometry

FIG. 2. Schematic illustration of the experimental procedures used to monitor processing of psoralen-induced damage at the gene-specific level. During RAGE, unmodified DNA and DNA containing psoralen MAs are denatured by alkali treatment and migrate at the position of single-stranded (ss) fragments. Extensive in vitro UVA irradiation converts psoralen MAs into XLs. Psoralen-cross-linked DNA is resistant to alkali denaturation and migrates at the position of double-stranded (ds) fragments. (a) Initial levels of MAs and XLs are determined immediately after PUVA-1 treatment by using the RAGE technique; (b) the repair efficiency is determined by comparing the initial level of damage with the level of damage remaining in unreplicated (LL) DNA $24 \mathrm{~h}$ after psoralen treatment. The efficiency of replicational bypass is determined by comparing the level of damage remaining in LL DNA with the level of damage remaining in replicated (HL) DNA $24 \mathrm{~h}$ after treatment. Brd Urd, bromodeoxyuridine; Frd Urd, fluorodeoxyuridine. 
b

$$
\text { PUVA - } 1 \text { Treatment }
$$

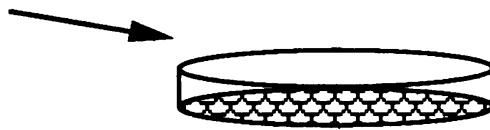

Lyse cells immediately,

or after $24 \mathrm{hrs}$ in BrdUrd + FrdUrd

Isolate high mol.w t.DNA,

Digest with restriction endonuclease
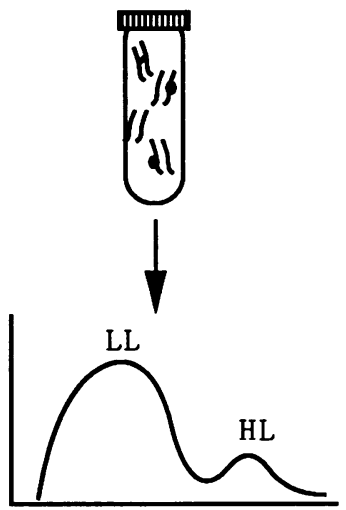

CsCl sedimentation

LL
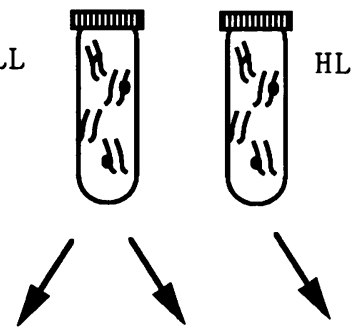

Repair RAGE
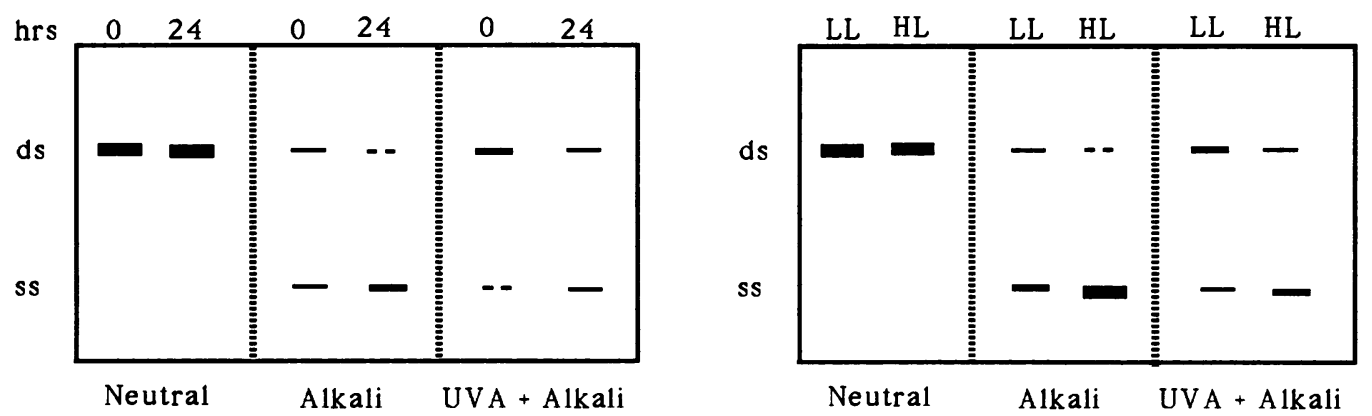

Transfer DNA to nylon membrane

Hybridize with 32P-labelled Probe - Autoradiograph and quantitate band intensities by densitometry

FIG. 2-Continued. 
a

\section{NORMAL CELLS}
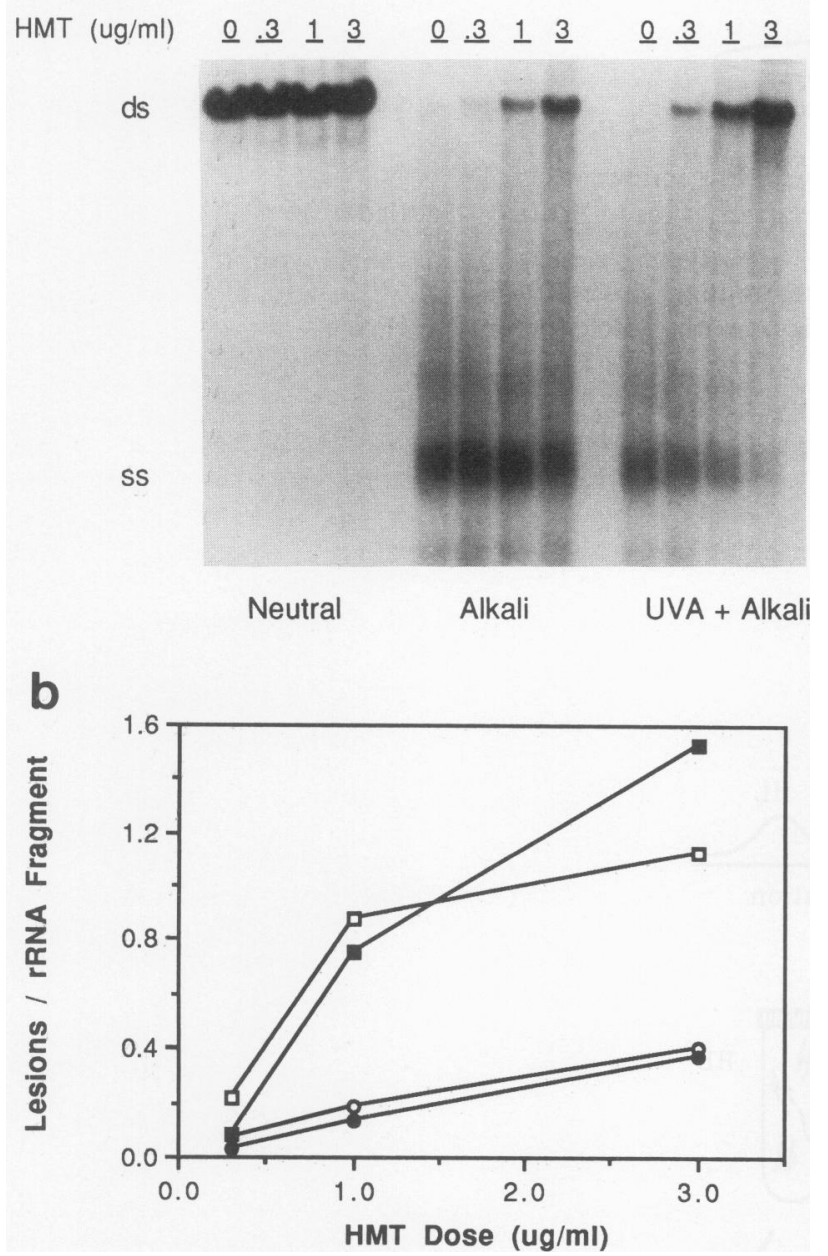

approximately half that in the unreplicated DNA. This finding reflects efficient bypass replication. In contrast, the fraction of cross-linkable DNA appeared to be much lower in the replicated DNA of XPV cells than in the unreplicated DNA. As indicated in Table 1, 72 to 84\% of HMT MAs were bypassed in normal cells, but only 36 to $51 \%$ of these lesions were bypassed in XPV cells. This result corresponds to 45\% deficiency in bypass of psoralen MAs in the XPV line. In addition, careful examination of the gels presented in Fig. 5 also revealed that a fraction of psoralen XLs were also bypassed during normal DNA replication; while an average of $40 \%$ of XLs were found in replicated DNA of normal cells (Table 1), no such bypass of psoralen XLs was detected in the XPV cell line. Taken together, these results indicate that a defect in bypass replication of psoralen adducts may be responsible for XPV hypersensitivity to PUVA-1.

\section{DISCUSSION}

XPV hypersensitivity to psoralen MAs. We report that XPV cells are hypersensitive to photoactivated psoralen. In doseresponse studies monitoring psoralen-induced inhibition of cell growth, we determined that XPV cells are especially

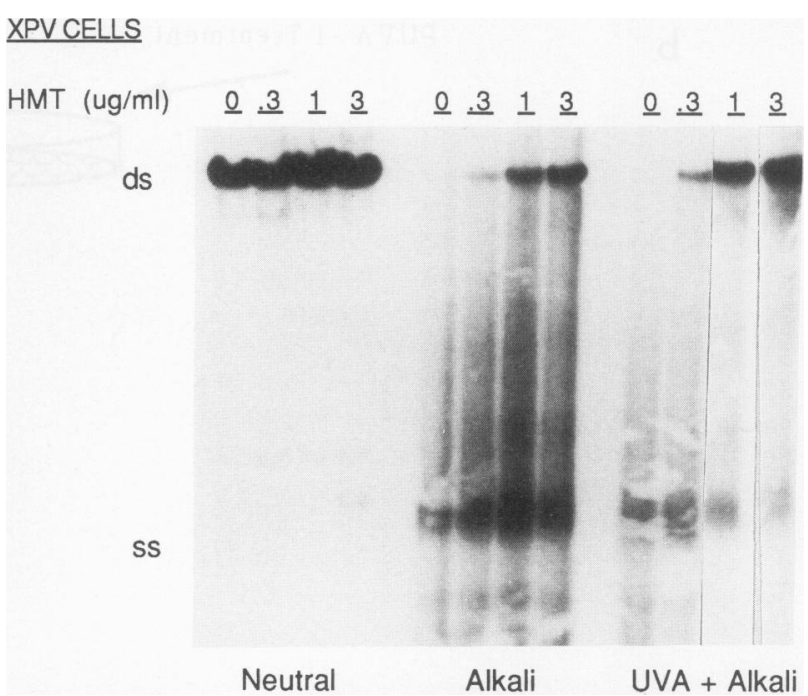

FIG. 3. Cellular susceptibility to HMT-induced modification of DNA. (a) Normal and XPV cells were lysed immediately after treatment with various doses of photoactivated HMT, and DNA was isolated, digested with endonuclease $E c o$ RI, and analyzed by RAGE. Following Southern transfer to nylon membranes, DNA was hybridized with a probe that detects a $10.7-\mathrm{kb}$ fragment spanning the region immediately upstream from, and including, the $5^{\prime}$ end of the rRNA gene. Levels of psoralen adducts are visualized as renatured double-strand bands in lanes labeled at the bottom as Alkali for XLs and UVA + Alkali for MAs. Markers on the left indicate the migration positions of double-stranded (ds) and single-stranded (ss) DNA fragments. (b) Summary of results from the experiments shown in panel a. Quantitative analysis of the autoradiograms was done by scanning densitometry as described in Materials and Methods. Filled and open circles represent XL levels in normal and XPV cells, respectively; filled and open squares represent MA levels in normal and XPV cells, respectively.

hypersensitive to HMT MAs in DNA. Enhanced sensitivity to psoralen MAs would be predicted if such lesions were to act as efficient blocks to DNA replication in XPV cells but not in normal cells. Similarly, the fact that XPV hypersensitivity to psoralen XLs was less pronounced may indicate that XLs arrest replication comparatively well in both cell types. The finding that XPV cells are hypersensitive to psoralen adducts contrasts with reports that XPV cells are not hypersensitive to another bulky chemical agent, benzo[ $a]$ pyrene diol epoxide (BPDE) $(1,5)$. However, since BPDE adducts are bypassed rather inefficiently in normal cells, it is quite conceivable that the XPV defect affects a bypass pathway that does not operate on lesions induced by BPDE (5). Alternatively, a BPDE bypass deficiency may fall below the limit of detection in XPV cells. The present study, along with those documenting XPV hypersensitivity to UV light $(4,17,23)$ but only mild sensitivity to other chemicals $(7,19)$, provide indirect evidence that the proteins involved in replicational bypass of DNA damage may discriminate between the various lesions in the mammalian genome. Since photoactivated HMT produces adducts with cyclobutyl rings to pyrimidines that are structurally quite similar to UV-induced pyrimidine dimers (3), it is possible that the efficiency of replication bypass in human cells varies with the nature of the structural deformation into DNA. Intriguingly, a similar pathway for the processing of DNA damage 


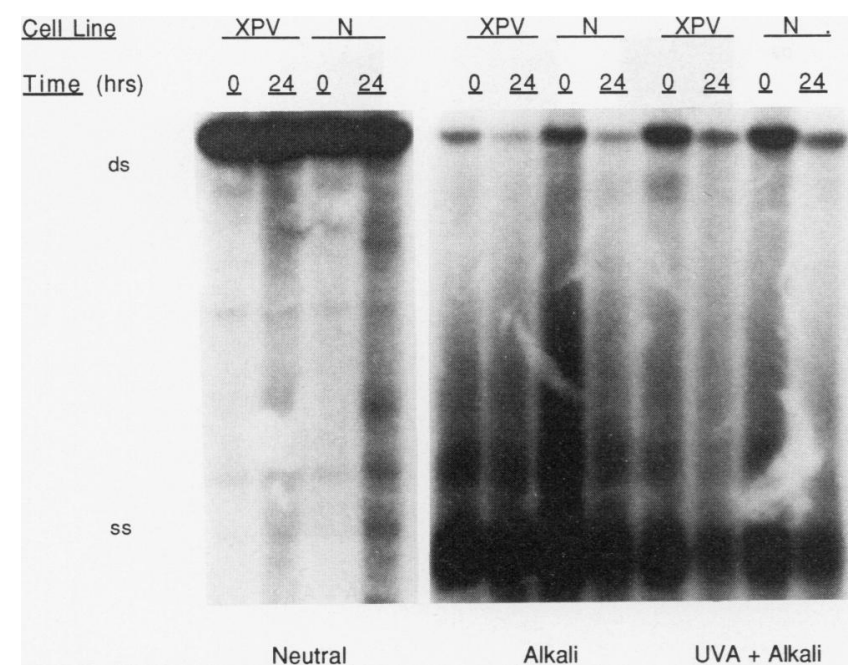

FIG. 4. Repair analysis of psoralen adducts in the rRNA genes of normal and XPV cells. Cell lines and incubation times after PUVA treatment are indicated at the top. Repair of psoralen adducts is visualized by comparing the amount of renatured double-strand bands between samples 0 and 24 in lanes labeled either Alkali for XLs or UVA + Alkali for MAs. Markers ds and ss on the left indicate the positions of double-stranded and single-stranded DNA fragments, respectively. Genomic DNA was isolated from growing cultures of normal HSC93 or XPV cells 0 and $24 \mathrm{~h}$ after treatment with $0.3 \mu \mathrm{g}$ of photoactivated HMT per ml. After EcoRI restriction and purification by $\mathrm{CsCl}$ equilibrium density gradient centrifugation, samples of parental DNA (LL) were loaded on a nondenaturing agarose gel as either native DNA, alkali-denatured DNA, or alkalidenatured DNA after in vitro UVA irradiation for $30 \mathrm{~min}$. After electrophoresis, Southern transfer, and hybridization with the rRNA probe, the filter was exposed to XR film with an intensifying screen.

induced by UV or PUVA has been reported with use of human cell transformation by integrative plasmids as the biological endpoint (34).

Processing of psoralen-induced adducts in normal and XPV cells. When psoralen-induced modification was assessed in a region just upstream the rRNA gene, no difference between normal and XPV lines was detected. In addition, similar levels of PUVA damage between the two cell lines were observed in other transcribed or nontranscribed fragments of the rRNA loci (data not shown). Thus, the DNA of normal and XPV cells appears to be equally accessible to modification by HMT. More important, no difference in the ability to remove DNA damage was detected between normal human and XPV cells. Although a number of recently isolated excision repair genes have been shown to be mutated in classical cases of XP (28), our findings indicate that XPV hypersensitivity to PUVA is not caused by a deficiency in excision repair. Heterogeneity in DNA repair at the species-, cell-, gene-, strand-, and lesion-specific levels has been well documented (reviewed in references 25 and 32). Specifically, we have previously shown that psoralen XLs are removed more efficiently than MAs in actively transcribed genes in a variety of mammalian fibroblasts $(33,35,38)$. Similar results were obtained in the present study using human lymphoblastoid cells. Between the two different types of lesions, HMT XLs may induce a greater degree of kinking in cellular DNA and therefore may be more easily recognized by the proteins involved in excising damage. Alternatively, normal cells may have evolved a particularly proficient system for removing XLs from DNA in order to compensate for the inefficient bypass of XLs during replication.

By examining the persistence of psoralen-induced damage in newly synthesized DNA, we discovered that XPV cells are markedly deficient in the ability to bypass psoralen adducts during replication. Although we cannot completely rule out the possibility that XPV cells lack a specific, replication-coupled mechanism of excision repair, several pieces of evidence argue against such a hypothesis. Theoretically, a defect in the ability to remove adducts during replication would result in an increased level of modification in partially replicated fragments of DNA. In our experimental scheme, this effect would appear either as higher levels of damage in the LL fraction of DNA in XPV versus normal cells or as a higher level of bypass replication in the defective versus the normal cell line; in the present study, neither result was observed. In addition, the frequency and spectrum of mutations induced on a shuttle vector exposed to UV light and allowed to replicate in normal and XPV cells have recently been reported (37); this study demonstrated significant differences in the kinds of mutations induced in normal versus XPV cells. Such findings further support the conclusion that XPV cells are not deficient in excision repair but that such cells do lack an efficient, error-free mechanism for bypassing DNA damage during replication. Thus, such faithful replication must function to suppress short-term toxicity and long-term carcinogenesis in normal human cells.

This study indicates that replication pathways of intrastrand MAs and interstrand XLs in human cells may share at least one gene product, the XPV protein. In addition, the loss of the ability to replicate XLs in XPV cells, together with recent evidence that both MAs and XLs induce sister chromatid exchange (6), may suggest that the XPV defect affects a translesional mechanism involving recombination (32). A recombination-related defect is proposed because it is difficult to imagine a simpler alternative mechanism for error-free bypass of XLs. At least two distinct recombination pathways for bypass replication in human cells have been proposed $(2,10,32)$. The first involves generalized recombination between the damaged and the undamaged DNA daughter molecules similar to the prokaryotic postreplication repair process; the other invokes a reversible strand-switching mechanism whereby a blocked new strand anneals with the unblocked new strand of the daughter molecule, replicates this undamaged template strand, and reanneals with its original damaged parental strand (for details, see the review in reference 32). In either case, the process may involve a continuous or gap-filling replication/recombination pathway. Thus, XPV could be defective in any of these processes. Alternatively, the XPV defect may affect a regulatory component of nuclear replication which is indirectly involved in bypass replication, such as progression through the $\mathrm{S}$ phase and/or de novo activation of stress replicons.

Finally, the finding that XPV cells are $45 \%$ deficient in the ability to bypass psoralen MAs suggests two additional possibilities: either the XPV syndrome is caused by a leaky mutation or the XPV defect affects only one strand of duplex DNA (32). Partial deficiencies in human syndromes are not uncommon (12); in such cases, complete mutations may be lethal, or too toxic, to allow proper development of an individual. On the other hand, current models of replication in human cells suggest that different DNA polymerases and/or accessory factors operate on different strands of 
a

NORMALCELLS

XPVCELLS

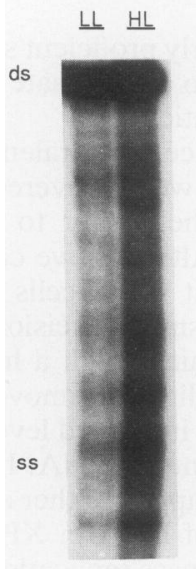

Neutral
$\underline{\mathrm{LL}} \quad \mathrm{HL}$

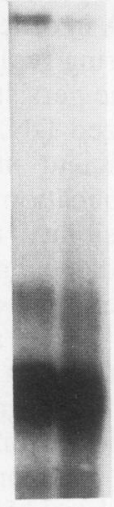

Alkali
$\underline{\mathrm{LL}} \quad \mathrm{HL}$

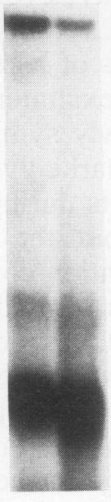

UVA + Alkal
$\underline{\mathrm{LL}} \underline{\mathrm{HL}}$

ds

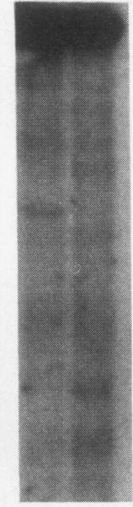

Neutral
$\underline{L L} \quad \underline{H L}$

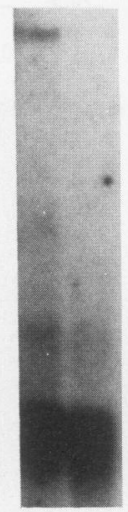

Alkali
$\underline{\mathrm{LL}} \underline{\mathrm{HL}}$

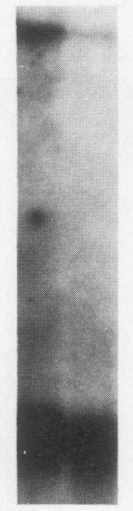

UVA + Alkali

b

NORMAL CELLS

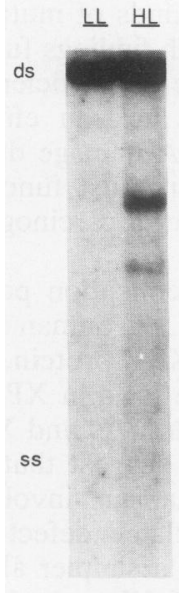

Neutral
$\underline{\mathrm{LL}} \underline{\mathrm{HL}}$

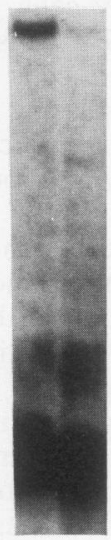

Alkali

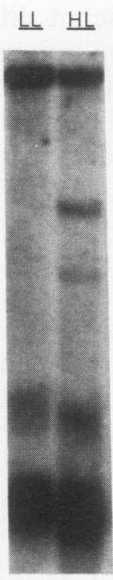

UVA + Alkali

XPVCELLS

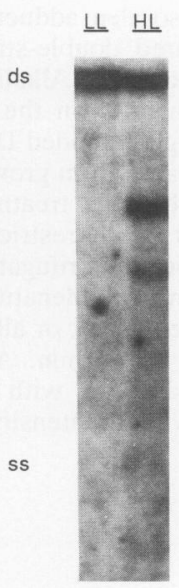

Neutral

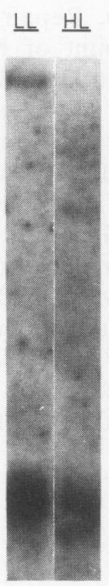

Alkali

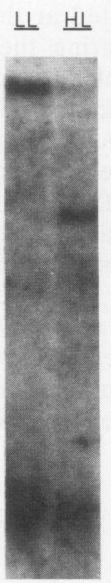

UVA + Alkali

FIG. 5. Replication analysis of psoralen adducts in the rRNA genes of normal and XPV cells. Replication bypass of psoralen adducts is visualized by comparing samples HL and LL of lanes labeled either Alkali for XLs or UVA + Alkali for MAs. Growing cultures of normal HSC93 or XPV cells were treated either 0.3 (a) or 1 (b) $\mu \mathrm{g}$ of photoactivated HMT per ml, and genomic DNA was isolated $24 \mathrm{~h}$ after treatment. After EcoRI restriction and separation by density gradient centrifugation of unreplicated (LL) and replicated (HL) DNAs (indicated at the top), samples were loaded on a nondenaturing agarose gel electrophoresis either native, alkali denatured, or alkali denatured after in vitro UVA irradiation (indicated at the bottom). After electrophoresis, Southern transfer, and hybridization with a radiolabeled rRNA probe, the filters were exposed to XR film with an intensifying screen. Positions of the double-stranded (ds) and single-stranded (ss) probed fragments are indicated at the left.

TABLE 1. Deficiency in replicational bypass in the rRNA genes of XPV cells

\begin{tabular}{|c|c|c|c|c|c|c|c|c|}
\hline Cell line & HMT dose & DNA fraction & $\mathrm{RF}^{a}$ & $\mathrm{XL}^{b}$ & $\mathrm{RF}_{\mathrm{uva}}$ & $\mathrm{XL}_{\text {uva }}$ & $\mathrm{MA}^{c}$ & Bypass efficiency \\
\hline HSC93 & 0.3 & LL & 3.93 & 0.040 & 7.30 & 0.076 & 0.036 & \multirow{2}{*}{72.2} \\
\hline XPV & 0.3 & $\begin{array}{l}\text { HL } \\
\text { LL }\end{array}$ & $\begin{array}{l}1.22 \\
1.20\end{array}$ & $\begin{array}{l}0.012 \\
0.012\end{array}$ & $\begin{array}{r}2.44 \\
10.18\end{array}$ & $\begin{array}{l}0.025 \\
0.107\end{array}$ & $\begin{array}{l}0.013 \\
0.095\end{array}$ & \\
\hline HSC93 & 1.0 & $\begin{array}{l}\text { HL } \\
\text { LL }\end{array}$ & $\begin{array}{c}\mathrm{ND}^{e} \\
14.85\end{array}$ & $\begin{array}{c}\text { ND } \\
0.161\end{array}$ & $\begin{array}{r}1.67 \\
51.28\end{array}$ & $\begin{array}{l}0.017 \\
0.719\end{array}$ & $\begin{array}{l}0.017 \\
0.558\end{array}$ & 35.8 \\
\hline XPV & 1.0 & $\begin{array}{l}\text { HL } \\
\text { LL }\end{array}$ & $\begin{array}{l}1.79 \\
7.25\end{array}$ & $\begin{array}{l}0.018 \\
0.075\end{array}$ & $\begin{array}{l}22.32 \\
26.09\end{array}$ & $\begin{array}{l}0.253 \\
0.302\end{array}$ & $\begin{array}{l}0.235 \\
0.227\end{array}$ & 84.2 \\
\hline & & HL & ND & ND & 5.66 & 0.058 & 0.058 & 51.1 \\
\hline
\end{tabular}

a Determined according to equation 4.

$b$ Determined according to equation 1 .

$c$ Determined according to equation 2 .

$d$ Determined according to equation 5 .

e ND, not detected. 
DNA (18), and a leading-strand versus lagging-strand bias affecting the fidelity of eukaryotic replication has already been proposed $(29,36)$. Studies to determine whether the XPV defect is strand specific or partial on both strands are currently under way in our laboratory.

\section{ACKNOWLEDGMENTS}

We thank Katherine Hamil for excellent technical assistance, Michael Topal for critically reading the manuscript, Amy Moore for secretarial assistance, and members of the laboratory for helpful discussions.

This research was supported in part by grants from the Life and Health Medical Research Fund and the Elsa U. Pardee Foundation and by NCI grant 1-R01-CA51096 to J.-M.H.V. R.R.M. was supported by NCI postdoctoral core training grant CA09156. J.-M.H.V. is a recipient of a Basil O'Connor Starter Scholar Research Award from the March of Dimes (5-813) and an American Cancer Society Junior Faculty Award (JFRA-330).

\section{REFERENCES}

1. Boyer, J. C., W. K. Kaufmann, B. P. Brylawski, and M. Cordero-Stone. 1990. Defective post replication repair in xeroderma pigmentosum variant fibroblasts. Cancer Res. 50:25932598.

2. Cesarone, C. F., C. Bolognesi, and L. Santi. 1979. Improved microfluorometric DNA determination in biological material using 33258 Hoechst. Anal. Biochem. 100:188-197.

3. Cimino, G. D., H. B. Gamper, S. T. Isaacs, and J. E. Hearst. 1985. Psoralens as photoactive probes of nucleic acid structure and function: organic chemistry, photochemistry and biochemistry. Annu. Rev. Biochem. 54:1151-1194.

4. Cleaver, J. E., and K. H. Kraemer. 1989. Xeroderma pigmentosum, p. 2949-2971. In C. R. Scriver, A. L. Beaudet, W. S. Sly, and D. Valle (ed.), The metabolic basis of inherited disease, part II. McGraw-Hill, New York.

5. Cordero-Stone, M., J. C. Boyer, B. A. Smith, and W. K. Kaufmann. 1986. Xeroderma pigmentosum variant and normal fibroblasts show the same response to the inhibition of DNA replication by benzo[a]pyrene-diol-epoxide-I. Carcinogenesis 7:1783-1786.

6. Cortes, F., W. F. Morgan, E. R. Varcarel, J. E. Cleaver, and S. Wolff. 1991. Both cross-links and monoadducts induced in DNA by psoralens can lead to sister chromatid exchange formation. Exp. Cell Res. 196:127-130.

7. D'Ambrosio, S. M., and R. B. Setlow. 1978. Defective and enhanced postreplication repair in classical and variant xeroderma pigmentosum cells treated with $\mathrm{N}$-acetoxy-2-acetylaminofluorene. Cancer Res. 38:1147-1153.

8. Echols, H., and M. F. Goodman. 1991. Fidelity mechanisms in DNA replication. Annu. Rev. Biochem. 60:477-511.

9. Erickson, J. M., and R. D. Schmickel. 1985. A molecular basis for discrete size variation in human ribosomal DNA. Am. J. Hum. Genet. 37:311-327.

10. Friedberg, E. C. 1985. DNA repair, p. 459-504. W. A. Freeman \& Co., New York.

11. Fujiwara, Y., A. Matsumoto, M. Ishihashi, and Y. Satoh. 1987. Heritable disorders of DNA repair: xeroderma pigmentosum and Fanconi's anemia. Curr. Probl. Dermatol. 17:182-198.

12. Gelehater, T. D., and F. S. Collins. 1990. Principles of medical genetics, p. 97-121. Williams \& Wilkins, Inc., Baltimore.

13. Grisham, J. W., D. S. Greenberg, D. G. Kaufman, and G. J. Smith. 1980. Cycle-related toxicity and transformation in 10T $1 / 2$ cells treated with $\mathbf{N}$-methyl-N'-nitro-N-nitrosoguanidine. Proc. Natl. Acad. Sci. USA 77:4813-4817.

14. Hanawalt, P. C., and A. Sarasin. 1986. Cancer-prone hereditary diseases with DNA processing abnormalities. Trends Genet. 2:124-129.

15. Higuchi, R., H. D. Stang, J. K. Brown, M. O. Martin, M. Huot, J. Lipeles, and W. Salser. 1981. Human ribosomal RNA gene spacer sequences are found interspersed elsewhere in the genome. Gene 15:177-186.

16. Konze-Thomas, B., R. M. Hazard, V. M. Maher, and J. J. McCormick. 1982. Extent of excision repair before DNA synthesis determines the mutagenic but not the lethal effect of UV radiation. Mutat. Res. 94:421-434.

17. Lehman, A. R., S. Kirk-Bell, C. F. Arlett, M. C. Paterson, P. H. M. Lohman, E. A. De Weerd-Kastelein, and D. Bootsma. 1975. Xeroderma pigmentosum cells with normal levels of excision repair have a defect in DNA synthesis after UVirradiation. Proc. Natl. Acad. Sci. USA 72:219-223.

18. Linn, S. 1991. How many pols does it take to replicate nuclear DNA? Cell 66:185-187.

19. Maher, V. M., N. Birch, J. R. Otto, and J. J. McCormick. 1975. Cytotoxicity of carcinogenic aromatic amides in normal and xeroderma pigmentosum fibroblasts with different DNA repair capabilities. J. Natl. Cancer Inst. 54:1287-1294.

20. Matsumoto, A., J.-M. H. Vos, and P. C. Hanawalt. 1989. Repair analysis of mitomycin C-induced DNA crosslinking in ribosomal RNA genes in lymphoblastoid cells from Fanconi's anemia patients. Mutat. Res. 217:185-192.

21. Meneghini, R., C. F. M. Menck, and R. I. Schumacher. 1981. Mechanisms of tolerance to DNA lesions in mammalian cells. Q. Rev. Biophys. 14:381-432.

22. Moshell, A. N., R. E. Tarone, S. A. Newfield, A. D. Andrews, and J. H. Robbins. 1981. A simple and rapid method for evaluating the survival of xeroderma pigmentosum lymphoid lines after irradiation with ultraviolet light. In Vitro 17:299 307.

23. Park, S. D., and J. E. Cleaver. 1979. Postreplication repair: questions of its definition and possible alteration in xeroderma pigmentosum cell strains. Proc. Natl. Acad. Sci. USA 76:39273931.

24. Schimke, R. T., S. W. Sherwood, A. B. Hill, and R. N. Johnson. 1986. Overreplication and recombination of DNA in higher eukaryotes: potential consequences and biological implications. Proc. Natl. Acad. Sci. USA 83:2157-2161.

25. Smith, C. A., and I. Mellon. 1990. Clues to the organization of DNA repair systems gained from studies of intragenomic repair heterogeneity, p. 153-194. In G. Obe (ed.), Advances in mutagenesis research, vol. 1. Springer-Verlag, Berlin.

26. Somerville, J. 1986. Nuclear structure and ribosome biogenesis. Trends Genet. 2:438-442.

27. Sylvester, J. E., D. A. Whiteman, R. Podolsky, J. M. Pozgav, J. Respess, and R. D. Schmickel. 1986. The human ribosomal RNA genes: structure and organization of the complete repeating unit. Hum. Genet. 73:193-198.

28. Thompson, L. H. 1991. Properties and applications of human DNA repair genes. Mutat. Res. 247:213-219.

29. Trinh, T. Q., and R. R. Sinden. 1991. Preferential DNA secondary structure mutagenesis in the lagging strand of replication in E. coli. Nature (London) 352:544-547.

30. Vermeulen, W., M. Stefani, S. Giliani, J. H. J. Hoeijmakers, and D. Bootsma. 1991. Xeroderma pigmentosum complementation group $\mathbf{H}$ falls into complementation group $\mathbf{D}$. Mutat. Res. 255:201-208.

31. Vos, J.-M. H. 1988. Analysis of psoralen monoadducts and interstrand crosslinks in defined genomic sequences, p. 367 398. In E. C. Friedberg and P. C. Hanawalt (ed.), DNA repair: a laboratory manual of research procedures. Marcel Dekker, New York.

32. Vos, J.-M. H. 1992. Cis and trans mechanisms of DNA repair. Curr. Opin. Cell Biol. 4:385-395.

33. Vos, J.-M. H., and P. C. Hanawalt. 1987. Processing of psoralen adducts in an active human gene: repair and replication of DNA containing monoadducts and interstrand cross-links. Cell 50: 789-799.

34. Vos, J.-M. H., and P. C. Hanawalt. 1989. DNA interstrand crosslinks promote chromosomal integration of a selected gene in human cells. Mol. Cell. Biol. 9:2897-2905.

35. Vos, J.-M. H., and E. Wauthier. 1991. Differential introduction of DNA damage and repair in mammalian genes transcribed by RNA polymerases I and II. Mol. Cell. Biol. 11:2245-2252. 
36. Vrieling, H., M. L. van Rooijen, N. A. Groen, M. Z. Zdzienicka, J. W. I. M. Simons, P. H. M. Lohman, and A. A. van Zeeland. 1989. DNA strand specificity for UV-induced mutations in mammalian cells. Mol. Cell. Biol. 9:1277-1283.

37. Wang, Y. C., V. M. Maher, and J. J. McCormick. 1991. Xeroderma pigmentosum variant cells are less likely than nor- mal cells to incorporate dAMP opposite photoproducts during replication of UV-irradiated plasmids. Proc. Natl. Acad. Sci. USA 88:7810-7814.

38. Wauthier, E., P. C. Hanawalt, and J.-M. H. Vos. 1990. Differential repair and replication of damaged DNA in ribosomal RNA genes in different CHO cell lines. J. Cell Biochem. 43:173-183. 